\title{
Análise da evolução da tecnologia: uma contribuição para o ensino da ciência e tecnologia
}

Luiz Augusto Hayne luizhayne2012@gmail.com 0000-0003-2671-1348 Universidade Federal do Rio Grande do Sul, Porto Alegre, RS

Angela Terezinha de Souza Wyse wyse@ufrgs.br

0000-0001-8769-1147

Universidade Federal do Rio

Grande do Sul, Porto Alegre, RS

\begin{abstract}
RESUMO
Apesar de a tecnologia ser uma ferramenta indispensável às conquistas humanas, falta pleno entendimento da sua evolução no tempo. A literatura analisa o progresso tecnológico num contexto pré-estabelecido e pontual, conseqüência do aspecto cultural, econômico, político e social que influencia o esforço humano na geração de tecnologias. A compreensão desta evolução se apresenta como importante para a educação científica e tecnológica baseada na ideia de que C\&T e sociedades são dois sistemas interligados e interdependentes. A partir de uma pesquisa bibliográfica sobre $C \& T$, não se pretendeu fazer o estudo do progresso tecnológico, que é condicionado a contextos particulares de um dado momento, mas uma análise que considerou um único processo, a história da humanidade. Como resultado identificamos cinco fases de mudanças na evolução da tecnologia através dos tempos. Concluiu-se que o dinamismo tecnológico, fruto da evolução da tecnologia, diminuiu o tempo das quatro primeiras fases (primitiva ou de subsistência, artesanal ou manufatureira, mecanizada ou industrial e de automação ou de ponta) no processo histórico e que a última (ética ou de sustentabilidade) revelou-se uma alternativa ideal que conduzirá os destinos da humanidade voltados ao progresso humano.
\end{abstract}

PALAVRAS-CHAVE: Tecnologia. Evolução da tecnologia. Progresso tecnológico. Ensino de Ciência e Tecnologia 


\section{INTRODUÇÃO}

A afirmação de que o conhecimento é o caminho para as descobertas tem nos guiado através dos tempos e nos auxiliado na resolução dos problemas que enfrentamos. Porém, por outro lado, o conhecimento também é responsável pelos descaminhos que a humanidade, em determinados momentos, resolveu seguir. $\mathrm{O}$ fato é que, independentemente das intenções, o conhecimento foi a chave para atender os interesses do homem em todas as épocas.

É nesse sentido que um entendimento abrangente do fenômeno "tecnologia" oferece um nível de conhecimento necessário para sua melhor aplicação. O que se pode afirmar, a princípio, é que a tecnologia é um fenômeno associado ao conhecimento. Gagne (2013:3) afirma que tecnologia é "conhecimento sistemático derivado da pesquisa científica". Ainda conforme este autor e em uma visão mais restrita, a tecnologia pode significar um processo contínuo e crescente de novas coisas, processos e ideias.

A gestão tecnológica é uma atividade que as instituições têm adotado como forma de gerenciamento dos recursos limitados disponíveis para obtenção dos melhores usos na geração das tecnologias para atendimento de nossas necessidades e desejos. As necessidades ligadas à solução dos problemas e os desejos ligados ao aumento do bem-estar.

Neste sentido, uma análise evolucionária da tecnologia vai ao encontro dos objetivos daqueles responsáveis pela condução do progresso tecnológico, a partir da compreensão do processo histórico que envolve a geração das tecnologias.

A tarefa de realizar uma análise histórica da evolução da tecnologia não é simples, pois há uma dificuldade em se determinar momentos marcantes ou "divisores de águas" que indiquem pontos de mudança ou rupturas quando se analisa esta evolução.

Ao se propor uma evolução histórica da tecnologia, não se pretende fazer uma análise do progresso tecnológico por si só e esse é o ponto central deste estudo. 0 progresso tecnológico é conseqüência da geração de novas tecnologias que estão inseridas em contextos ambiental, social, cultural, econômico e político próprios de uma sociedade, ou seja, o progresso tecnológico é resultante do estado da arte de determinado momento e local na história humana.

É objetivo deste estudo analisar, em uma nova perspectiva, como esse progresso tecnológico, resultante de condições próprias e específicas, evoluiu no tempo. Essa investigação tem como escopo a identificação das principais etapas da história da evolução da tecnologia, procurando caracterizar e delimitar as fases que criaram as condições propícias para a realização do progresso tecnológico através dos tempos.

O desenvolvimento social, que desde os primórdios experimentou fases e mudanças, retrata a complexidade na análise do comportamento humano e tem forte ligação com a evolução da tecnologia. Em sua odisséia através dos tempos a tecnologia serviu às vezes como causa, pois ela influenciou o comportamento do homem (determinismo tecnológico) e, às vezes como conseqüência, onde o homem influenciou nesta evolução, interferindo no progresso tecnológico. O determinismo tecnológico, segundo Grint e Woolgar (2013) indica que o comportamento humano e o próprio curso da história, são largamente 
determinados, mais do que determinantes, pela tecnologia. Já para Veraszto et al. (2008) a tecnologia pertence, atua, molda e sofre interferências do meio em que está inserida.

Por outro lado, Jayaweera apud Grint e Woolgar (2013) argumenta que a tecnologia só é possível onde há o encontro de circunstâncias sociais, políticas e econômicas às quais garantem a sua exploração e conversão para um poderoso instrumento social e econômico. Pacey apud Sandler (2014) afirma que a implementação de novas tecnologias atende a um contexto social que permite uma boa adaptação de seu uso.

É importante, portanto, evitar-se uma visão fatalista acerca da tecnologia, uma posição determinista que considere os sistemas tecnológicos como que dotados de autonomia, chegando a dominar a vida humana". Ainda para este autor "através de uma percepção sócio-histórica podemos perceber a complexidade das relações entre a tecnologia, a política, a economia, a cultura (Marx apud Queluz e Queluz, 2000:6).

Portanto, são questões teóricas que ainda deixam alguma lacuna em relação ao papel da ciência e da tecnologia e a sua relação com a sociedade, onde aspectos culturais, ambientais, econômicos, políticos e sociais podem sofrer influência da dinâmica do desenvolvimento científico e tecnológico ou geram consequências sobre o sistema gerador de ciência e tecnologia.

Nos últimos dois séculos esse discurso encontra autores que procuraram explicar o fenômeno da tecnologia, e da ciência que a alimenta, na explicação das mudanças sociais, baseadas principalmente no entendimento das forças produtivas, das condições sociais e do emprego dos meios de produção.

Em um primeiro momento, o pensamento estava focado na neutralidade da ciência e de acordo com Merton (CARMINHA e ANDION, 2017) a ciência é uma atividade autônoma e neutra, influenciada e inserida em um contexto social. Nesse contexto, questões políticas, econômicas ou culturais em nada interfeririam o desenvolvimento do conhecimento.

A partir da revolução industrial, a contribuição de Marx e de seus seguidores contrapunham a neutralidade científica, abandonando de forma radical a ideia de que C\&T não determinariam o comportamento social. $O$ determinismo tecnológico, já citado, era a representação da ideologia capitalista, onde os detentores dos meios de produção determinariam o comportamento da sociedade, a partir das relações sociais geradas pelas forças produtivas, em um ambiente onde o lucro capitalista seria o estímulo principal não só de empresas, mas do próprio Estado. Para Lima (2001), sociólogos, principalmente a partir da segunda grande guerra, afirmaram que "as mudanças tecnológicas ultrapassam a habilidade das pessoas e das diversas sociedades para adaptar-se a elas".

Estudos mais recentes apontam para a não neutralidade da C\&T em um contexto mais voltado para as mudanças observadas na sociedade, sobretudo no pós-guerra, onde o caráter político começa a exercer uma forte pressão sobre a estrutura responsável pela geração do conhecimento e da sua aplicação. Essa percepção vai contra, segundo Dagnino (2002), de que a C\&T não oferece alternativas, dada uma única orientação baseada no determinismo tecnológico. Autores de tendência socialista, como Holloway e Peláez (1990:29) em uma forte oposição ao que se chama de pós-fordismo, contexto que emerge uma nova ordem 
capitalista baseada na última revolução tecnológica a partir dos anos 50, argumentam que "o desenvolvimento tecnológico, assim como outros aspectos do desenvolvimento social, é marcado pela tentativa sempre contraditória do capital de colocar arreios na criatividade humana".

Tendo como foco a sociedade, vários autores desenvolveram a ideia de que há uma ambigüidade dessa estrutura com a ciência e a tecnologia, onde se observa momentos em que a mudança social interfere na trajetória tecnológica e onde a C\&T determinam algum comportamento social.

Nesse contexto, aparecem duas teses que confrontam a neutralidade da ciência e o determinismo tecnológico, ancorados na ideia de que o ambiente movido por relações sociais e econômicas, aliados ao interesse político, conformam o ambiente onde a ciência e a tecnologia são desenvolvidas e como as diferentes sociedades se utilizam desses desenvolvimentos (DAGNINO, 2002).

A tese fraca da neutralidade da C\&T que tem no construtivismo a sua base teórica, advoga que as mudanças sociais, sejam ou influenciadores ou influenciadas pela trajetória tecnológica, têm no imperativo político, um fator determinante para a constituição do modelo de desenvolvimento que a sociedade busca encontrar. Para Winner apud Dagningo (2002:11) “C\&T não são neutras, já que podem ter implicações sociais e políticas, nem são endogenamente determinadas, já que sua concepção pode estar afetada pelo contexto sócioeconômico". A noção do construtivismo estaria apoiada à ambiguidade observada na via de mão dupla que tanto a sociedade e a C\&T poderiam criar, dependendo das demandas identificadas no processo de desenvolvimento social.

No caso da tese forte da não neutralidade da C\&T, autores como Coriat (1976) e Dickson (1980), acrescentaram ao contexto político-sócio-econômico, o ingrediente cultural. A tese forte pode ser melhor entendida, quando se observa na construção do pensamento marxista, a transição do capitalismo para o socialismo. Basicamente, como o desenvolvimento da ciência e tecnologia no capitalismo esteve estruturado na cultura da dominação e da alienação, o socialismo teria problemas para se firmar na transição ao comunismo, dada a necessidade de adaptação a um modelo de desenvolvimento onde o caráter científico e tecnológico estava baseado nessa cultura. Nesse contexto, o caráter político seria fundamental para o encontro de uma alternativa que atendesse a ideologia socialista, diametralmente oposta à ideologia capitalista.

Uma forte crítica à neutralidade da ciência e tecnologia e ao fortalecimento da tese forte é o que expõe Coriat ao se alinhar com Dickson e acrescentar que o fracasso do socialismo real está na insistência de uma forte corrente soviética em replicar o mesmo padrão capitalista de produção, tendo como base teórica a neutralidade da ciência e da tecnologia. Nessa linha defende que "consideradas em seu duplo aspecto de métodos de organização do trabalho e de "coisas" (meios de produção), as forças produtivas levam o carimbo e a marca das relações sociais nas que estão inscritas e nas quais foram sido produzidas" (CORIAT,1976 p. 84). Basicamente a tese forte direciona para o fato de que a funcionalidade da C\&T inibirá as mudanças sociais dada a dificuldade de sua adaptação em diferentes contextos aos quais não foram desenvolvidas (DAGNINO, 2009).

O discurso acima apresentado nos leva a acreditar que a evolução da tecnologia, dada a sua complexidade, experimentou fases e mudanças que estabeleceram bases fundamentais no curso do desenvolvimento humano. Apesar 
da dificuldade na análise de um processo histórico da evolução tecnológica e até mesmo social, podemos identificar alguns princípios que facilitam a compreensão desta evolução e orientam a pesquisa em torno do entendimento que se pretende chegar com o presente estudo.

O primeiro é a afirmação de que o desenvolvimento humano e o tecnológico estão paralelamente associados. Segundo Sandroni (1989:274), "tecnologia é uma teoria ou ciência da técnica. Abrange o conjunto de conhecimentos aplicados pelo homem para atingir determinados fins". Portanto, a tecnologia sempre esteve presente no convívio humano. Para Veraszto et al. (2008:61) "a história da tecnologia está estreitamente ligada a história do homem, e por isso, é bastante complexa e com inúmeras ramificações."

O segundo é que a tecnologia, por servir às nossas necessidades e desejos, adquiriu a partir de certo momento do progresso social, uma relação indissociável com o progresso econômico. Mais precisamente e de maneira mais sistematizada, a partir da Revolução Industrial no século XVIII. Marqueti (2002:104) defende que "o principal fator do crescimento de um país é o progresso técnico."

O terceiro é a ideia de que o aparecimento de novas tecnologias não deve ser aceito como fruto, único e exclusivo, da engenhosidade de um grande inventor que com suas invenções, contribuiu para as mudanças sociais, pois as tecnologias passadas influenciam e interferem na geração das tecnologias presentes. Neste sentido, Basalla (1993) criou a metáfora darwinista da evolução das espécies pela seleção e adaptação para explicar o comportamento da tecnologia. A utilização de um modelo evolucionista, para ele, na análise das mudanças tecnológicas serviu para confirmar o caráter cumulativo do conhecimento e sua implicação na geração das novas tecnologias e, por conseguinte, do progresso tecnológico.

Nesta linha de pensamento identificamos três grandes inovações revolucionárias ${ }^{1}$ que para Sandroni (1989:274) "em termos históricos amplos a expressão designa uma transformação radical no âmbito das forças produtivas, modificando profundamente a relação do homem com a natureza, e conseqüentemente, o modo de existência de toda a sociedade" e que para o presente estudo, estão incluídas nas fases evolucionárias da tecnologia a serem apresentadas a seguir e que afetaram "os progressos tecnológicos" quando se observa as épocas em que ocorreram.

\section{UMA CONTRIBUIÇÃO AO ENSINO DA CIÊNCIA E TECNOLOGIA}

O papel que a C\&T tem desenvolvido na sociedade é mais nítido quando se observa a transformação das formas de compreensão do desenvolvimento do conhecimento e a sua relação com a sociedade. A noção de que a ciência é neutra e a tecnologia determinística passa a ser uma concepção de que o contexto que envolve a geração do conhecimento é descolado daquele que envolve as mudanças sociais.

Página | 41

Os estudos desenvolvidos no último século, por outro lado, colocaram o fenômeno da C\&T mais "mundano" baseado na assertiva de que sociedade e C\&T

\footnotetext{
${ }^{1}$ A primeira das grandes inovações foi marcada pela invenção da máquina a vapor no auge da Revolução Industrial no século XVIII; a segunda pela invenção do motor elétrico no final do século XIX; e a última pela utilização produtiva dos conhecimentos de eletrônica, da computação, da automação e da energia atômica no século XX (SANDRONI, 1989:274).
} 
se interconectam e são interdependentes. Por isso, mais do que uma área de estudo que teria como interessados, cientistas, sobretudo sociais, o ensino da ciência e tecnologia torna-se um imperativo para a compreensão e formação cidadã que coloca o tema no centro do debate político, pelas implicações sociais, econômicas e culturais que o fenômeno de fato revela.

A educação científica e tecnológica passa a ser uma importante ferramenta para a compreensão das mudanças sociais onde o caráter endógeno da geração do conhecimento deve ser interpretado como uma disciplina que agrega aos indivíduos, além do conhecimento em si, uma perspectiva crítica que poderá durante o processo de formação educacional, permitir uma visão holística do processo de desenvolvimento humano baseado no conhecimento e em sua aplicação. Linsingen e Suzani (2010) afirmam que a educação tecnológica permite uma inserção social naqueles assuntos em que a $C \& T$ estejam envolvidas a partir de uma participação mais ativa nos processos de tomada de decisões.

O distanciamento observado entre $C \& T$ e sociedade por aqueles filósofos que em épocas precedentes inauguraram os estudos sobre a ciência ideal (filosofia da ciência) deixa de existir quando se observa movimentos em torno do aprofundamento do papel da ciência e da tecnologia no desenvolvimento social e, por fim, humano. As modernas concepções desenvolvidas pela sociologia da ciência, levam à necessidade de não somente compreender o fenômeno mas, sobretudo, de disponibilizá-lo para a sociedade.

Nessa linha Angotti e Auth (2001:18) em relação à importância que a C\&T têm na vida das pessoas afirmam que "compreender mais e melhor as problemáticas de influência direta no modo de vida da população não pode se restringir ao estudo das relações sociais em curso. Estudos que apontem e aprofundam perdas e danos resultantes dos processos da ciência aplicada e da tecnologia são também essenciais, nas dimensões coletivas e individuais".

O papel do ensino da ciência e tecnologia passa a ter um caráter discursivo onde uma hegemonia da neutralidade e do determinismo é obscurecida pela problematização e pela dialogicidade, implicando em importantes mudanças na educação (LISINGEN e CASSIANI, 2011:169).

Portanto, considerar o tema na formação de currículos educacionais se converte em uma ação que visa uma estratégia de desenvolvimento nacional. Estudos têm sido desenvolvidos nessa linha com destaque para o Grupo Discursos da Ciência e Tecnologia na Educação/DICITE da Universidade Federal de Santa Catarina/UFSC, preocupados com a participação social a partir de programas educacionais e por meio da mudança de visão quanto à natureza do fenômeno científico e tecnológico para a transformação social (LISINGEN e CASSIANI, 2011:163). Entre os temas mais estudados pelo DICITE estão incluídos a Educação Tecnológica e das Engenharias; a Formação Humanística na Educação Tecnológica; a Tecnologia Social e abordagens alternativas da Educação Tecnológica; a semiótica visual na Educação Tecnológica; a educação ambiental em perspectiva CTS; a teoria Ator-Rede; a análise sóciotécnica; a teoria crítica da Tecnologia e a educação tecnológica (Ibid., p.173).

É na intenção de contribuir para o conhecimento da relação entre C\&T, sociedade e desenvolvimento humano que o presente estudo foi formulado com a convicção de que se entender de forma mais aprofundada essa relação, fortalece o processo de ensino da ciência e tecnologia. 


\section{UMA ANÁLISE EVOLUCIONÁRIA DA TECNOLOGIA}

As figuras 1 e 2 a seguir, resultados do presente estudo e elaboradas pelos autores, sintetizam os objetivos desse estudo. A Figura 1 mostra as fases da evolução da tecnologia durante a história. A tecnologia é onipresente e molda todos os aspectos da experiência humana, se convertendo em guia das mudanças sociais e ecológicas. A influência da tecnologia em nossas vidas e as taxas de geração de inovações tecnológicas vêm crescendo ao longo da história (SANDLER, 2014).

Veraszto (2004) afirmou que por meio da evolução histórica das técnicas, se pode compreender de que forma, conjuntamente, homem e tecnologia agem ativamente objetivando o progresso.

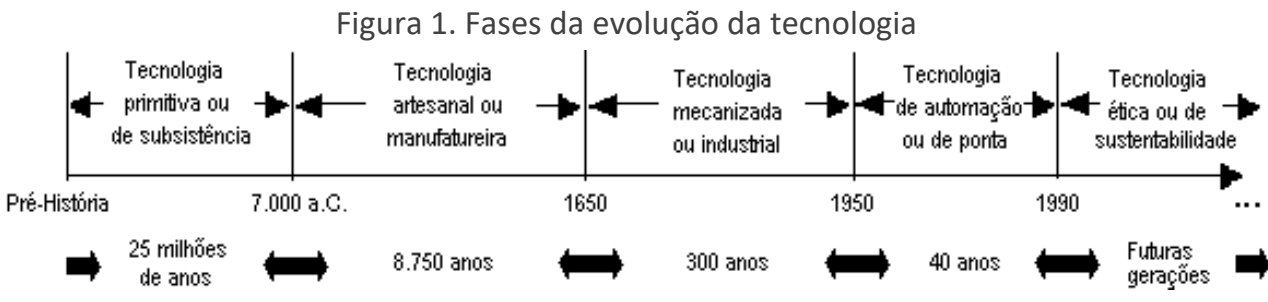

(Fonte: elaborada pelos autores)

Obs.: a figura tem como objetivo demonstrar as fases sem a preocupação de definir proporcionalmente a linha de tempo).

Foram identificadas cinco grandes fases que se relacionam a períodos específicos na história da humanidade. A análise revela que elas envolvem e definem contextos históricos, ou seja, parte-se da suposição de que as fases da evolução da tecnologia determinaram as condições propícias para o progresso tecnológico.

Em uma análise das teorias apresentadas e que procuram relacionar ciência, tecnologia e sociedade, as fases apresentadas nesse estudo indicam que as perspectivas teóricas levam à aceitação das teses da não neutralidade da C\&T. Porém, se definem três momentos na análise dessas teses.

O primeiro, na origem do processo histórico de evolução da tecnologia da Figura 1 na fase primitiva ou de subsistência, em que o conhecimento humano, ainda rudimentar e pré-histórico, baseava-se mais pelo instinto de sobrevivência, embora sob alguma base racional, do que na concepção de um arcabouço de conhecimento ordenado. Nessa fase inicial não se pode argumentar de tese fraca ou forte da não neutralidade, porque sequer podemos falar de sociedade, dado o estágio de desenvolvimento humano precário e incipiente. Nessa fase se pode falar mais da relação homem/natureza do que homem/sociedade, em que as tecnologias geradas atendiam tão somente a necessidade de sobrevivência humana.

Em um segundo momento da análise histórica, que vai da tecnologia artesanal ou manufatureira até a tecnologia de automação e de ponta, já se vislumbra o ápice do desenvolvimento humano baseado na C\&T. Ainda na fase pré-industrial, com a formação primitiva de capital baseada nas relações de comércio global (mercantilismo) e no primeiros movimentos de uma globalização, as mudanças sociais eram intensas e o componente tecnológico já era visto como fator 
importante de tais mudanças, sobretudo após o apogeu do capitalismo, das teses do determinismo tecnológico e do seu contraponto, a partir dos autores socialistas que defendiam o que conceituou Feenberg (1991), de uma ambivalência tecnológica em que novos atores podem provocar alterações no desenho estabelecido e modificar conhecimentos produzidos em um dado contexto. Essas são evidências de que a melhor explicação para a relação entre ciência, tecnologia e sociedade nesse sub-período está na tese fraca da não neutralidade.

Em um terceiro momento, com o reconhecimento de que o modelo de produção baseado na acumulação do capital, no desenvolvimento tecnológico e no crescimento econômico, gerou um ponto de inflexão da trajetória tecnológica, pois emergiu a necessidade de compreensão das consequências geradas pela imposição da reprodução do capital baseada, para muitos autores, no determinismo tecnológico. Como defendem Holloway e Poláez (1990:29) "como parte da sociedade, a tecnologia mostra todas as contradições do desenvolvimento social". Acrescenta-se a isso as consequências negativas sobre o meio ambiente, que juntos, forçaram a uma revisão do modelo de desenvolvimento adotado.

Portanto, ao analisarmos as teses da não neutralidade da C\&T, a fase da tecnologia de subsistência ou de sustentabilidade estaria mais alinhada com a tese forte da não neutralidade, pois além do caráter ambíguo da relação entre ciência, tecnologia e sociedade, oriunda da tese fraca, é imperativo a geração de tecnologias alternativas (sociais e ambientais). Para tanto é necessário a formulação de políticas que estejam compromissadas com a nova realidade em um ambiente novo em que o mainstream seja radicalmente alterado. Para Dagnino (2002:22) "essa tecnologia alternativa deveria ser baseada nos objetivos de obter modos de produção social não opressores e não manipuladores e uma relação não predatória com o meio ambiente natural".

Considerando o exposto e a afirmação de que, independentemente das teorias que explicam a relação entre ciência, tecnologia e sociedade, a Figura 2 abaixo apresenta a perspectiva de que o progresso tecnológico ocorreu em todas as épocas e a identificação das fases da evolução da tecnologia tipifica esse progresso de acordo com as características particulares de determinada época e contexto histórico.

Figura 2. As fases da evolução da tecnologia e o progresso tecnológico

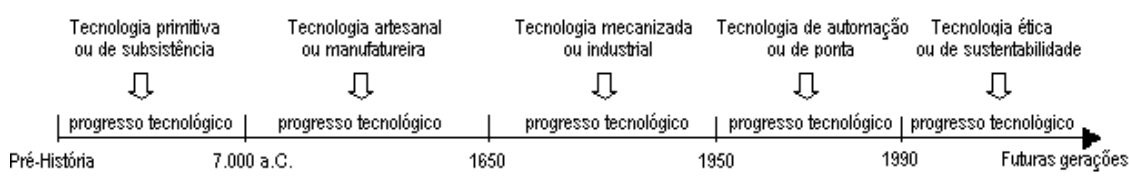

(Fonte: elaborada pelos autores)

$\mathrm{Na}$ história da evolução da tecnologia observa-se, a princípio, um ritmo bastante lento que teve início na era pré-histórica e se estendeu até a formação das primeiras sociedades mais organizadas na Antiguidade, definindo a fase da tecnologia primitiva ou de subsistência. 
Um ritmo maior pôde ser observado até o final da Idade Média, onde o aumento das cidades e a intensificação do comércio aceleraram a produção de novas tecnologias, determinando a fase da tecnologia artesanal ou manufatureira.

A partir da Era Moderna a tecnologia apresentou um ritmo bastante acelerado e a mecanização foi responsável pelo aparecimento de um grande número de máquinas e produtos que promoveram a indústria e a economia e marcaram a fase da tecnologia mecanizada ou industrial.

Após a terceira revolução industrial ou revolução tecnológica na primeira metade do século $X X$, a automação adquiriu papel fundamental nos processos produtivos e o ritmo das inovações alcançou uma velocidade com taxas crescentes de progresso econômico até nossos dias, definindo a fase da tecnologia de automação ou de ponta.

Finalmente, um novo padrão tecnológico iniciado no fim do último século, vem ganhando espaço no meio produtivo e está relacionado à necessidade de preservação do meio ambiente, alterando significativamente o processo de geração de tecnologias. A fase da tecnologia limpa ou de sustentabilidade tende a ser o padrão tecnológico que guiará os destinos da humanidade.

Alguns pontos devem ser ressaltados para a adequação de nossa análise evolutiva da tecnologia:

a) as fases identificadas não se sobrepõem nos momentos em que estão estruturadas ou "maduras";

b) elas têm características cumulativas, ou seja, para a existência de uma é necessário a preexistência da outra; e

c) admite-se que na transposição de uma fase para a outra há uma convivência mútua em que a velha, gradualmente, cede espaço à nova até a sua total extinção e a conseqüente estruturação da fase substituta em um processo de destruição criadora.

O ritmo crescente e envolvente da dinâmica tecnológica levou a uma redução do tempo de cada fase. À medida que a sociedade evoluiu, mais conhecimento foi agregado e convertido em novas tecnologias. Estas estimularam o progresso social que, mais uma vez, agregou mais conhecimento, formando um círculo virtuoso cada vez mais poderoso.

Isso pode ser observado na Figura 1 onde o comportamento evolucionário apresentado mostra que a fase da tecnologia primitiva ou de subsistência durou aproximadamente 25 milhões de anos, desde o aparecimento do primeiro homem até 0 ano 7.000 a.C.

O tempo se reduziu na fase da tecnologia artesanal ou manufatureira, que se iniciou na Antiguidade e foi até o século XVII durando, aproximadamente, 8.750 anos.

O impulso tecnológico observado na fase da tecnologia mecanizada ou industrial com início no fim da Idade Média, durou aproximadamente 300 anos, finalizando na metade do século XX.

Na quarta fase, que cobriu a década de 50 até o final dos anos 90 do século $X X$, o tempo de duração da fase da tecnologia de automação ou de ponta levou apenas 40 anos. $O$ reduzido período de tempo é explicado pelas conseqüências da 
adoção do modelo de produção e será explorado mais detalhadamente na próxima seção.

Por fim, como resposta às condições desfavoráveis atuais e como alternativa de solução destas implicações, apareceu a quinta e última fase da evolução intitulada tecnologia limpa ou de sustentabilidade, com início no final do século XX e, de acordo com esse estudo, espera-se seja definitiva e garanta às futuras gerações um ambiente saudável com promoção da qualidade de vida a todos.

Como forma de um entendimento mais apurado sobre as características de cada fase, procederemos a seguir um aprofundamento na análise de cada uma delas.

\section{FASES DA EVOLUÇÃO DA TECNOLOGIA}

\subsection{TECNOLOGIA PRIMITIVA OU DE SUBSISTÊNCIA}

Há milhões de anos o homem já habitava a terra e para sobreviver, fazia uso da natureza como fonte de alimento, moradia e vestuário. As necessidades levaram a mente humana, mesmo na mais primitiva forma, ao encontro da solução de problemas vitais.

A Pré-História surgiu com o aparecimento do primeiro homem que se tem notícia, indo até o surgimento das primeiras civilizações orientais (cerca do ano 7.000 a.C.). Pode-se identificar três períodos da Pré-História em que o homem alcançou o progresso (SANDRONI, 1989).

O primeiro refere-se ao período Paleolítico ou era da Pedra Lascada que era caracterizada por uma vida gregária do homem; pela inexistência de propriedade privada; e pela distribuição igualitária do produto do trabalho coletivo.

Este período marcou o início da fase da tecnologia primitiva ou de subsistência, orientada apenas para o sustento. As ferramentas eram construídas para a coleta dos frutos e raízes no caso de vegetais, e para caça de pequenos animais, no caso de alimentos de origem animal. Para Veraszto et al. (2008) o uso de ferramentas foi um dos fatores mais importantes que explicam a existência de nossos ancestrais primitivos. Veraszto (2004:23) advoga que "precisamos lembrar que a nossa histórica do homem tecnológica começou junto com o primeiro quando ele descobriu que era possível modificar a natureza para melhoras as condições de vida de seu grupo."

A tecnologia empregada foi desenvolvida a partir de instrumentos feitos de pedra lascada ${ }^{2}$. Com o passar do tempo, aprimoramentos foram sendo efetuados e o homem primitivo fabricava machados mais aperfeiçoados, lanças, arpões e anzóis.

Veraszto et al. (2008:63) argumentam em relação ao homem primitivo que "somente através do emprego de sua capacidade intelectual primitiva é que foi capaz de estabelecer relações fundamentais que o auxiliaria a modificar o meio, empregando uma técnica até então inexistente".

\footnotetext{
2 Um exemplo é o machado primitivo feito com lascas de pedra fixadas por cipó em um pedaço de madeira, muito utilizado para a caça e a
} defesa. 
Nesta primeira fase, a característica de subsistência vinculada à tecnologia relacionava-se às habilidades de um homem caçador que tinha como necessidade primária, a alimentação e sua segurança.

O segundo período é o Neolítico ou era da Pedra Polida, marcado pela moradia em cavernas. Com o progresso tecnológico o primata desenvolveu melhoramentos na matéria-prima (pedra) o que possibilitou a fabricação de um número maior de materiais e utensílios úteis à sua sobrevivência.

O homem do neolítico desenvolveu a técnica de tecer panos, de fabricar cerâmicas e construiu as primeiras moradias, constituindo-se os primeiros arquitetos do mundo. Conseguiu ainda, produzir o fogo através do atrito e deu início ao trabalho com metais.

Houve o início da vida em sociedade, principalmente às margens dos rios no Oriente Médio e a agricultura desenvolveu-se. O homem nômade, em conseqüência, começou a se fixar nas terras.

Estes fatos marcaram o início do terceiro período do homem primitivo, conhecido como Idade dos Metais (cobre, ferro e bronze). Nesta fase, a sofisticação permitiu a construção da roda, do arado e do artesanato em cerâmica.

O homem dominou o fogo e a metalurgia desenvolveu-se com as técnicas de transformação dos metais em utensílios domésticos, de caça e para produção, principalmente agrícola.

A fixação do homem e a invenção dos instrumentos agrícolas geraram excedentes de produção. As trocas comerciais entre tribos estimularam o desenvolvimento de técnicas para o transporte dos produtos.

Neste período primitivo, apesar do homem não ter o conhecimento científico, foi capaz de utilizar a tecnologia para a realização de seus interesses.

Apesar da filosofia e da ciência ainda estarem longe de serem desenvolvidas, a mente humana primitiva, ainda que por instinto de sobrevivência e de forma bastante rudimentar, explorava a tecnologia disponível e a colocava em um papel que até hoje prevalece, o atendimento às necessidades humanas.

Em uma forma particular, por mais rudimentar que fosse, a tecnologia primitiva foi o elo entre o homem e a natureza. A inteligência pré-histórica foi capaz de transformar a natureza em atividades humanas essenciais tais como a fabricação de utensílios para a caça, a pesca, a construção e o artesanato. Vivendo sozinho, na era mais primitiva, ou em sociedade, no final da era Pré-Histórica, o homem já explorava a tecnologia.

\subsection{TECNOLOGIA ARTESANAL OU MANUFATUREIRA}

Esta fase se divide em duas partes. A primeira inclui a Antiguidade e a segunda a Idade Média.

Na primeira parte, a filosofia teve forte influência no desenvolvimento da técnica e das formas de convívio social.

As várias correntes filosóficas da Antiga Grécia buscavam respostas sobre a existência do Universo e do próprio ser. Isso se refletiu na sociedade e nas relações predominantes do aspecto interativo entre o indivíduo e a natureza. 
As bases desta influência residem na racionalidade contra o místico e o metafísico. As conseqüências dessa forma de pensar tiveram forte impacto sobre a vida econômica, social e política das cidades.

As relações humanas na Antiguidade, balizadas na sabedoria e no conhecimento racional, levaram o homem a interagir com a natureza filosoficamente, na tentativa de se entender os fenômenos observados. Neste momento, Sócrates deslocou a reflexão filosófica da natureza para o homem e definiu o universal como objeto da ciência.

Como forma de ilustrar esta concepção, Platão criou o mito da caverna e desenvolveu a ideia de que ela representa o todo abstrato e o exterior, o todo concreto. O objetivo do homem é sair da caverna, ou seja, livrar-se do abstrato para a liberdade de contato com o físico, o concreto, o mundo racional. A filosofia seria a chave para esta libertação através do raciocínio concreto e não abstrato.

Sob influência desta forma filosófica de pensar, os indivíduos buscaram a satisfação de suas necessidades através do aprimoramento das técnicas em bases racionais.

As relações de troca nas cidades organizadas se dinamizaram e a organização política e administrativa culminou no aprimoramento das técnicas de produção e de distribuição.

Na segunda parte da fase da tecnologia artesanal ou manufatureira, a antiga filosofia grega baseada na razão como fonte de explicação do Universo, se alastrou por várias áreas do conhecimento e, em um movimento convergente, contribuiu para as práticas baseadas na ordenação econômica da sociedade medieval.

Na Idade Média, iniciada com a queda do Império Romano e assinalando o fim da Antiguidade, nasceu um novo modo social e econômico baseado na propriedade de grandes extensões de terras conhecido como o Feudalismo ${ }^{3}$.

O artesanato passou a ser uma importante atividade econômica e, mesmo existindo desde a Pré-História, atingiu um grau de relevância dentro da estrutura social feudal, impulsionando-a.

Os artesãos realizavam o trabalho na casa do campo ou no próprio castelo feudal, no interior dos feudos. Ainda não havia a divisão do trabalho verificada na Revolução Industrial e o artesão realizava todo o processo produtivo.

Nesta fase, houve ampla utilização de teares manuais, de ferramentas para tosquia, de máquinas de costura, além de implementos agrícolas para o cultivo e retirada de matéria-prima da terra. Mesmo para uma época rudimentar o progresso tecnológico atendia os interesses e as necessidades da sociedade medieval.

Com a Revolução Comercial ${ }^{4}$ e o desenvolvimento das cidades, houve uma transferência da atividade artesanal do campo para as cidades, que levaram à decadência da estrutura feudal, caracteristicamente agrária (SANDRONI, 1989).

\footnotetext{
3 Organização social e econômica típica da Idade Média européia, caracterizada pelo sistema de grandes propriedades territoriais isoladas (feudos) pertencentes à nobreza e ao clero e trabalhadas por servos da gleba, numa economia de subsistência (SANDRONI, 1989).

${ }^{4}$ Conjunto de transformações ocasionadas nas relações de troca entre a Europa e o resto do mundo no período que vai do século XV ao XVII. Decorreu da formação dos mercados nacionais e do desenvolvimento do comércio no continente europeu, a partir do século XI.
} 
As transformações tecnológicas modificaram a organização artesanal e o artesão, nas cidades, começou a trabalhar em ofícios como empregado.

As novas tecnologias revolucionaram a agricultura e, segundo vários historiadores, houve uma Revolução Agrícola ${ }^{5}$. Os efeitos foram sentidos sobre a sociedade medieval, desorganizando-a.

As relações sociais nos feudos, onde o senhor feudal mantinha a hegemonia sobre camponeses e aldeões, também foram alteradas. As revoluções tecnológicas transformaram o homem medieval em produtor de cereais, de lã e de carnes.

O progresso técnico auferido pelo aumento do comércio e das necessidades transformou o trabalho artesão em manufator. Com isso houve uma divisão do trabalho na produção, embora o artesão ainda atuasse ativamente no processo de transformação.

A partir de século XVII e no século XVIII, ocorreu o aperfeiçoamento das tecnologias de produção, baseada em estabelecimentos fabris, onde a técnica era artesanal, mas o trabalho era desempenhado por grande número de operários sob a direção de um empresário. Estes fatos abriram caminho ao novo período da história do desenvolvimento tecnológico baseado na divisão do trabalho e na mecanização.

O que se pode concluir desta fase da evolução da tecnologia é que o trabalho artesanal e manufatureiro foi uma característica básica das atividades produtivas econômicas ou não econômicas, que representaram uma importante fonte de criação e aprimoramento de tecnologias.

Conforme se pode observar na fase artesanal e manufatureira, a tecnologia deixou de ter uma importância apenas de subsistência, característica da fase anterior, e incorporou nas relações sociais da época, outras necessidades que estavam relacionadas ao aspecto econômico.

A tecnologia em sua jornada histórica aumentou sua participação na vida social e econômica de forma mais latente, a partir do aumento do fluxo comercial, da organização política e da liberdade do indivíduo, abrindo caminho para novas incursões do progresso.

\subsection{TECNOLOGIA MECANIZADA OU INDUSTRIAL}

Em uma fase mais desenvolvida, a tecnologia adquiriu um papel econômico e social mais relevante em sua evolução histórica. Este resultado teve suas raízes ligadas a três aspectos distintos e simultâneos:

No campo científico, o desenvolvimento da ciência foi observado com o aparecimento das novas doutrinas filosóficas que, principalmente nos séculos XVI e XVII, mudaram a ordem existente;

\footnotetext{
${ }^{5}$ Sob o interesse da tecnologia como elemento de pesquisa, pode-se encontrar um grande número de escritores sobre o assunto agrícola, que tratam de novas tecnologias como a drenagem, a semeadura, a rotação de colheitas e da criação de gado (SCHUMPETER, 1964).
} 
No campo político-social-cultural, o Renascimento ${ }^{6}$ dos séculos $\mathrm{XV}$ e XVI abriu caminho ao lluminismo ${ }^{7}$ no século XVIII, alterando as relações sociais e as formas do pensamento humano, que demandaram reformas e progressos orientados pela razão, em um ambiente caracterizado por uma desordem herdada de épocas precedentes. A Revolução Francesa em 1789 foi o ápice destas mudanças, e;

No campo econômico, as ideias mercantilistas, que tiveram início no século XVI a partir do Absolutismo e da criação dos Estados Nacionais, foram substituídas pela doutrina clássica da liberdade e da acumulação do capital como fator de desenvolvimento, estimulando a atividade industrial.

A união destes três pontos culminou no que foi conhecido como a Revolução Industrial, um conjunto de transformações tecnológicas, econômicas e sociais ocorridas na Europa entre os séculos XVIII e XIX.

O desenvolvimento das novas tecnologias está ligado ao modo de produção capitalista para o aumento da riqueza nacional através da industrialização, onde o capital se constituiu no principal fator do desenvolvimento industrial. Castelfranchi e Fernandes (2015:175) alertam para o fato de que "a produção e a apropriação do conhecimento científico e tecnológico sempre cumpriram um papel central no capitalismo moderno."

Com o aprimoramento tecnológico, a mecanização passou a ser a forma de produção das indústrias nascentes. $\mathrm{O}$ trabalho artesanal deixou de ser utilizado e a divisão do trabalho criou a linha de produção. Com isso, máquinas foram inventadas para cada fase do processo de produção a partir das novas tecnologias.

O modelo fabril substituiu o artesanal e observou-se um grande salto na produtividade que incentivou, ainda mais, a industrialização, que absorvia as tecnologias geradas nesta nova fase.

Com o aumento da riqueza nacional, viabilizado pela produção mecanizada, novos mercados foram sendo explorados, principalmente pela produção de artigos de consumo, que incrementou a produção de novas máquinas. Houve, ainda, a necessidade de mais aprimoramentos na área de siderurgia e no aperfeiçoamento dos processos de fundição, que se espalhou para outros setores.

O grande salto da tecnologia no período da Revolução Industrial foi a substituição da energia hidráulica pela máquina a vapor. A força motriz advinda da energia hidráulica limitava espacialmente a construção de fábricas próximas aos rios e causava problemas de abastecimentos em locais mais distantes (transporte, custos maiores, tempo entre produção e abastecimento), além de provocar problemas no fornecimento das matérias-primas que eram adquiridas em locais longínquos.

O progresso procedente desta tecnologia permitiu a construção de locomotivas e navios, que melhoraram o transporte e permitiram a interligação dos centros industriais aos mercados consumidores e das fontes de recursos

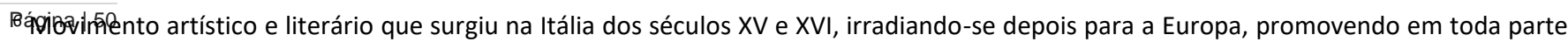
um pronunciado florescimento da arquitetura, escultura, pintura e das artes decorativas, da literatura e da música e um novo enfoque da política.

7 O lluminismo foi o ponto de partida para as revoluções sociais da Europa, onde a burguesia, contra o sistema feudal, procurava se estabelecer como classe dominante. Na Inglaterra, a burguesia foi responsável pela Revolução Industrial; na França, pela Revolução Francesa; e nos Estados Unidos, pela Guerra da Secessão. A luta pelo poder político consolidou-se a favor da burguesia contra o absolutismo monárquico e o regime feudal.
} 
naturais (matérias-primas) aos centros produtivos, gerando um círculo virtuoso no processo produtivo industrial.

A Europa, nesta época, foi palco de um crescente progresso científico em vários ramos do conhecimento oriundo do Renascimento. O desenvolvimento da eletricidade, por exemplo, foi responsável por novas tecnologias de comunicação como o cabo submarino e o telégrafo e a invenção do motor elétrico motivou uma segunda revolução industrial.

Os efeitos tecnológicos, porém, não foram responsáveis apenas pelos logros do homem na solução dos problemas presentes nesta fase da evolução da tecnologia. Barra et al. (2006:423) afirmam que "a industrialização trouxe consigo, além da modernização, o avanço tecnológico e a valorização da ciência em detrimento do homem e de seus valores."

Um sério problema que é uma barreira ao desenvolvimento social e econômico diz respeito ao desemprego gerado pelo progresso tecnológico, originário das mudanças tecnológicas de produção através da mecanização.

O desemprego não chegou a ser levado a sério na sociedade medieval, pois quando havia, limitava-se apenas a condições sociais insignificantes para o conjunto da sociedade, como os indivíduos marginalizados: indigentes, vagabundos e bandidos. A restrição acontecia quando ocorriam as convulsões sociais geradas pelas guerras ou doenças contagiosas (REZENDE, 1999).

Além disso, o nível tecnológico não pressionava a demanda por mão-de-obra porque a tecnologia artesanal foi insuficiente para alterar a composição do produto, garantindo à mão-de-obra a maior parcela.

Mesmo com a industrialização no século XVII, não houve uma equivalência entre oferta de trabalho e oferta de mão-de-obra, pois ela mais absorveu mão-deobra do que criou desemprego.

Os efeitos dos avanços tecnológicos sobre o nível de desemprego só foram sentidos a partir da segunda metade do século XVIII, onde a mecanização estava presente praticamente na totalidade das fábricas, marcando o apogeu da Revolução Industrial.

Para Schumpeter (1964) a miséria do trabalhador estava fortemente associada ao ritmo do desenvolvimento industrial que gerou o desemprego tecnológico e para Marx (1988) os efeitos da tecnologia industrial foram responsáveis pelo aparecimento do exército industrial de reserva.

Os resultados do desemprego tecnológico foram sentidos em movimentos do proletariado a favor da garantia do emprego e contra a mecanização. A revolta veio principalmente dos artesãos que foram afetados negativamente pelo avanço tecnológico ${ }^{8}$.

Independentemente dos efeitos positivos ou negativos, pode-se afirmar que a tecnologia nunca experimentou um período de tão grande progresso e a Revolução Industrial é um fato destacado para o rápido avanço tecnológico. 0

\footnotetext{
${ }^{8}$ No início do século XIX, grupos de operários ingleses destruíram as máquinas das indústrias têxteis. Com o emprego das máquinas, sucedeuse a ruína de milhares de artesãos que foram forçados a venderem sua força de trabalho aos capitalistas. Estes grupos ficaram conhecidos como os Luditas, que refere-se ao nome de King Ludd, um dos líderes da revolta.
} 
modo capitalista de produção necessitou dos aprimoramentos técnicos, via mecanização, para aumentar a produtividade da mão-de-obra e do próprio capital.

Os efeitos desta fase tiveram reflexos também no século XX e reforçaram a trajetória iniciada no século XVII pelas transformações tecnológicas que tiveram reflexos sobre a economia e sociedade na era moderna.

A fase da tecnologia mecanizada ou industrial creditou ao capitalismo a responsabilidade pela geração das novas tecnologias e a sua utilização em larga escala, criando uma íntima relação entre os progressos tecnológico e econômico.

A era da mecanização teve reflexos sobre as futuras gerações e o avanço científico e tecnológico levou a uma relevância do aspecto econômico ${ }^{9}$ sobre o social e influenciou o aparecimento da próxima fase do desenvolvimento da tecnologia.

\subsection{TECNOLOGIA DE AUTOMAÇÃO OU DE PONTA}

Com o desenvolvimento do sistema capitalista, a tecnologia deixou de ser um componente ou um fator de produção e passou a ser o elemento de distinção entre desenvolvimento e subdesenvolvimento.

Embora as origens das ideias capitalistas sob a égide do liberalismo econômico, remontam a Inglaterra do século XVIII, foram os Estados Unidos no início do século XX que impulsionaram o modelo de produção capitalista e, na sua esteira, o progresso tecnológico.

A noção de acumulação do capital abriu espaço a uma nova fase do capitalismo com o aparecimento da sociedade de consumo e com as novas ideias propostas pela administração científica que ganhou espaço no meio empresarial da época.

Estes fatos marcaram o enfraquecimento do modo de produção baseado na mecanização industrial e abriu espaço para o capitalismo pós-industrial, que impôs um novo padrão de desenvolvimento tecnológico para a produção de mercadorias e acirrou a concorrência entre empresas e nações na conquista de novos mercados consumidores.

O progresso científico estimulou a criação e o desenvolvimento tecnológico e a ciência e a tecnologia juntaram as mãos definitivamente. Tornou-se imperativo a todas as nações a formulação de políticas governamentais que estimulassem o aumento da capacidade científica e tecnológica o que, sem isso, marginalizaria quem não alcançasse níveis superiores de conhecimento e técnica.

As políticas de ciência, tecnologia e inovação (C\&T\&I), reconhecidamente aceitas como indispensáveis ao desenvolvimento do capitalismo pós-industrial, "são explicitadas pelos governos, em geral, extremamente condicionadas pelas políticas econômicas e industriais praticadas". (RODRIGUES, 1997).

Os governos elevaram o papel da tecnologia nas estratégias nacionais de desenvolvimento. Essa argumentação é reforçada com a opinião de Rodrigues (p.143) em que "evidenciou-se que a capacidade tecnológica tornara-se um fator

9A economia firmou-se como ciência a partir da metade do século XVIII, principalmente com a publicação de "A Riqueza das Nações", de Adam Smith, considerado o Pai da Ciência Econômica. A publicação da obra ocorreu no auge da Revolução Industrial. 
estratégico central, não somente para o poderio militar, mas, também e principalmente, para o desenvolvimento econômico, social e político".

Um grande salto dado pela tecnologia em seu processo evolutivo foi verificado na segunda metade do século XX, com o aparecimento do chip e dos circuitos integrados.

Este acontecimento, que para muitos correspondeu à terceira revolução industrial, dotou o sistema econômico de um forte elemento na capacidade de produção e inaugurou a fase intitulada tecnologia de automação ou de ponta, dando início a um novo ciclo tecnológico que marcou o começo da sociedade pósindustrial (BELL apud RODRIGUES, 1997).

Nos países industrializados a tecnologia de ponta se consistiu em forte razão para o alto investimento público e privado. O seu caráter intensivo levou as empresas a criarem laboratórios de pesquisa e desenvolvimento e a contratarem pesquisadores e tecnólogos, e os governos a destinarem grandes volumes de recursos orçamentários para formação e estruturação da capacidade científica e tecnológica.

O paradigma técnico-econômico baseado na tecnologia intensiva se alastrou por toda a cadeia produtiva e desenvolveu setores tradicionais, baseados na "velha" tecnologia, além de criar novos ramos com alto padrão tecnológico ${ }^{10}$.

O que foi prioridade na fase da tecnologia mecanizada passou a representar uma necessidade vital para setores que utilizam a tecnologia de automação ou de ponta. Nos referimos ao processo explícito de geração de inovações tecnológicas que corresponde na atualidade, uma demanda prioritária para as políticas de crescimento econômico das nações.

Para Rodrigues apud Revista Política e Científica (1997), "Schumpeter foi o primeiro a anunciar o papel primordial da tecnologia e inovação como motores do crescimento econômico". Em seu estudo sobre os ciclos econômicos, Schumpeter (1988) identificou que o início de um novo ciclo está associado ao aparecimento de inovações básicas.

O padrão de desenvolvimento baseado na inovação tecnológica criou uma forma de manifestação sistêmica para geração dos novos produtos. Com isso, a utilização da ciência e tecnologia para um sistema de inovação tecnológica, necessita da interação de vários seguimentos interdependentes no sistema.

Assim, entra no processo de inovação uma divisão de trabalho que inclui empresas sub-contratadas, laboratórios, entidades de apoio técnico, instituições de ensino de pesquisa, de marketing, de distribuição e financiamento.

Hoje vivenciamos um processo de globalização que de maneira ampla, significa a derrubada das barreiras econômicas entre as nações e é marcado pela livre mobilidade dos recursos produtivos (mão-de-obra, capital, recursos financeiros, tecnologia). Esse fenômeno ditou o padrão de desenvolvimento na fase da tecnologia de automação ou de ponta. 

tecnológica que se refere,

A adoção de estratégias globais de pesquisa, mediante a implantação de unidades de P\&D em diferentes países, estabelecimento de networks para inovação e mesmo os grandes programas de pesquisas transnacionais cooperativos desenvolvidos, sobretudo, pela União Européia e Japão, entre outros, são elementos considerados como constituintes do processo de tecnoglobalismo (LASTRES et al., 1999:45).

A tecnologia de ponta está no seio deste processo global e os seus efeitos inauguraram a Nova Economia ${ }^{11}$ baseada, exclusivamente, na produção tecnológica de alta sofisticação.

Em suma, a fase da tecnologia de automação ou de ponta foi marcada pelo enaltecimento do progresso tecnológico no contexto sócio-econômico-cultural e transferiu à tecnologia o centro das atenções de empresas, governos e sociedades, para a meta de obtenção de níveis superiores de qualidade de vida e de bem-estar, através do aumento da riqueza e da acumulação do capital.

\subsection{TECNOLOGIA LIMPA OU DE SUSTENTABILIDADE}

Como foi observado na fase anterior, a tecnologia foi a responsável por um dinamismo das economias dos países desenvolvidos da atualidade que alcançaram altas taxas de crescimento econômico.

A importância do seu papel para o crescimento econômico levou a um movimento global em torno da capacitação científica e tecnológica para geração das inovações tecnológicas, com vistas à acumulação do capital para a sustentação do modelo capitalista.

Porém, as conseqüências da adoção deste modelo tiveram repercussões negativas sobre um sistema altamente sensível e vital à manutenção da vida em nosso planeta: o meio ambiente. Na visão de Costa (2009) os ambientalistas em geral observaram um abismo entre as potencialidades da tecnologia para o crescimento econômico e a forma de organização social degradante do sistema capitalista e da ineficiência das instituições políticas, para a correção da relação destrutiva entre o homem o meio ambiente. Ainda nesta linha, em princípio, a evolução tecnológica era um contra-censo às manifestações favoráveis ao meio ambiente. (VALLEJO, 2015)

Na prática, a necessidade de produção e de consumo crescentes pressionou o meio natural na oferta dos recursos e matérias-primas indispensáveis para a realização desta produção.

Essa necessidade levou ao esgotamento de recursos naturais não renováveis, o desmatamento indiscriminado, a extinção de espécies vegetais e animais, a poluição do ar, rios e oceanos, tornou frágil o equilíbrio nas grandes cidades, alterou o clima ameaçando várias regiões e populações do planeta, como o problema da camada de ozônio e do efeito estufa entre outros.

\footnotetext{
${ }^{11}$ Para se ter uma ideia da importância da tecnologia neste novo contexto, basta verificarmos a existência de um mercado de ações exclusivo para as empresas de alta tecnologia, negociadas na Bolsa de Valores de New York. O índice Nasdaq acompanha este mercado, diferenciandose do índice Dow-Jones, que está vinculado à "velha economia".
} 
Com o aprofundamento da discussão ambientalista em um contexto social e econômico, a partir do melhor entendimento dos custos sociais e do lado negativo do progresso, abriu-se a possibilidade de assimilação dos problemas e da busca de suas soluções (VALLEJO, 2015).

Diante desse quadro, apareceu na segunda metade do século passado, um novo paradigma relacionado ao gerenciamento e exploração dos recursos disponíveis para atendimento das necessidades humanas, embora nos anos 70 muitos acreditavam na necessidade de interrupção do processo de desenvolvimento econômico (COSTA, 2009).

Esse paradigma, conhecido como desenvolvimento sustentável, está vinculado a um novo padrão de produção e consumo que tem como principal meta, a garantia da vida às futuras gerações.

Esse ponto marcou o início da fase da tecnologia limpa ou de sustentabilidade e vem confirmar que diante das duas faces relegadas ao progresso tecnológico, de herói e de vilão, há o reconhecimento do seu poder benéfico, desde que a sua geração e utilização incorporem a filosofia fundamental defendida pelo desenvolvimento sustentável. Costa (2009:18) afirma que "a ciência e a tecnologia são instrumentos centrais nesse processo, uma vez que depende delas a inovação de processos e produtos, nesse sentido, estas são bases da atual situação, tanto para problemas como possibilidades de mudança".

Além de possibilitar o uso inteligente do potencial tecnológico para os objetivos do desenvolvimento nacional, as tecnologias de sustentabilidade permitirão a preservação do meio ambiente e o seu uso orientado, no longo prazo, viabilizará o recondicionamento dos ecossistemas ${ }^{12}$. Para Vallejo (2015:12) "tecnologias apropriadas assumem um papel importante para o ecodesenvolvimento."

A estratégia que norteia as políticas de C\&T\&I deve acrescentar o termo "sustentabilidade" em sua formulação, exigindo dos agentes responsáveis pela sua execução uma nova postura, que considera uma reflexão sobre as conseqüências da geração e adoção de tecnologias sobre o meio ambiente e social e não somente sobre a competitividade econômica.

O Ministério do Meio Ambiente/MMA (1999) apontou as seguintes questões do papel da tecnologia no novo modelo de desenvolvimento: a política tecnológica deve estar orientada para gerar e promover o uso de tecnologias limpas; as ações e atividades afetas à política tecnológica devem atender adequadamente às necessidades da proteção e uso racional dos recursos naturais e na qualidade de insumos para as atividades econômicas; a política tecnológica deve promover a apropriação e utilização eficaz dos insumos produtivos; o sistema de inovação deve buscar soluções para diminuir o risco de deterioração ambiental; os aspectos sociais e humanos devem ser priorizados nas estratégias de geração e difusão de tecnologias.

Como se verifica, as políticas governamentais desempenham papel tecnológica e de know-how entre empresas, abrangendo a identificação,

\footnotetext{
${ }^{12}$ Muitas tecnologias de sustentabilidade já estão presentes nos nossos dias como os catalisadores dos automóveis, as embalagens e os produtos biodegradáveis, os processos de reciclagem, etc.
} 
avaliação, pesquisa e desenvolvimento, manejo, marketing, e a aplicação de produção mais limpa" (MINISTÉRIO DO MEIO AMBIENTE, p. 54).

O caráter sistêmico oriundo da fase anterior concretizou a necessidade da participação dos vários agentes identificados no Sistema Nacional de Inovação para a geração das tecnologias de sustentabilidade em um modelo de desenvolvimento sustentável.

Neste cenário, pesquisa e desenvolvimento continuam sendo um determinante da capacitação tecnológica e devem se transformar, estritamente, em objeto de demanda da política científica e tecnológica e, amplamente, da política nacional de desenvolvimento.

A Agenda 21 - C\&T para o desenvolvimento sustentável recomendou os seguintes pontos norteadores de uma política científica e tecnológica que priorize a inovação tecnológica de sustentabilidade (MINISTÉRIO DO MEIO AMBIENTE, 1999):

- estimular a indústria para que aumente e fortaleça sua capacidade de desenvolver tecnologias, produtos e processos seguros, menos poluentes e façam uso mais eficaz de todos os recursos e matérias-primas, inclusive da energia;

- cooperar no desenvolvimento e transferência dessas tecnologias industriais e no desenvolvimento de capacidades de gerenciar e usar tais tecnologias, particularmente no que diz respeito aos países em desenvolvimento;

- desenvolver e fortalecer as capacidades nacionais de pesquisa e de geração de tecnologias ambientalmente saudáveis, assim como adotar medidas para reduzir os resíduos ao mínimo.

- promover o desenvolvimento das capacidades de avaliação, desenvolvimento, manejo e aplicação de novas tecnologias. Isto exigirá o fortalecimento das instituições existentes, o treinamento do pessoal em todos os níveis e a educação dos usuários finais da tecnologia;

- estimular a avaliação de tecnologia mediante a utilização, por exemplo, em centros de avaliação tecnológica.

Um dos maiores desafios ligados à geração e à difusão das tecnologias de sustentabilidade é a aceitação deste novo estilo de comportamento que deve fazer parte da sociedade contemporânea.

A quebra de uma cultura que justifica os altos rendimentos econômicos pela consagração da inovação tecnológica como um dos pilares das economias industrializadas e pelo alto padrão de desenvolvimento e prosperidade alcançado pelas modernas nações industriais, passa a representar o maior desafio dos defensores do desenvolvimento sustentável.

O reconhecimento da importância das tecnologias de sustentabilidade apresenta-se, por um lado, pela identificação do meio ambiente como um elemento de grande relevância no modelo de desenvolvimento e, por outro, pela mudança da sólida cultura que defende o crescimento econômico a qualquer preço.

Atualmente existe uma vasta literatura que se ocupa da formulação de modelos, teorias e novos conceitos que se mostrem empiricamente válidos para a 
efetiva criação de tecnologias que atendam as necessidades relacionadas a esta última fase da evolução da tecnologia.

As chamadas Environmental Kusnetz Curves - EKC e as Resource Curve Hypothesis - $\mathrm{RCH}$ representam esse novo campo de estudo que evidencia a relação entre o crescimento econômico e o meio ambiente.

Neste ambiente econômico ideal o papel da tecnologia é entendido como indutor de um verdadeiro processo de desenvolvimento sustentável, opondo-se a tradicional ideia de que o crescimento econômico gera a degradação e o desequilíbrio ambiental.

Neste contexto a geração de tecnologias, se orientada para os interesses e necessidades da fase da tecnologia limpa ou de sustentabilidade, são um importante instrumento do desenvolvimento sustentável.

A Figura 3 desenvolvida por Egli (2005:60) para explicar o comportamento de uma curva poluição-renda U-invertida (Environmental Kuznetz Curve-EKC) e adaptada para este estudo mostra de que forma as mudanças tecnológicas endógenas se refletem no meio produtivo e se revertem em poderoso instrumento que possibilita ao crescimento econômico um efeito positivo sobre o sistema sócio-ambiental.

Figura 3. Modelo de transição tecnológica (da tecnologia “suja' para a tecnologia "limpa")

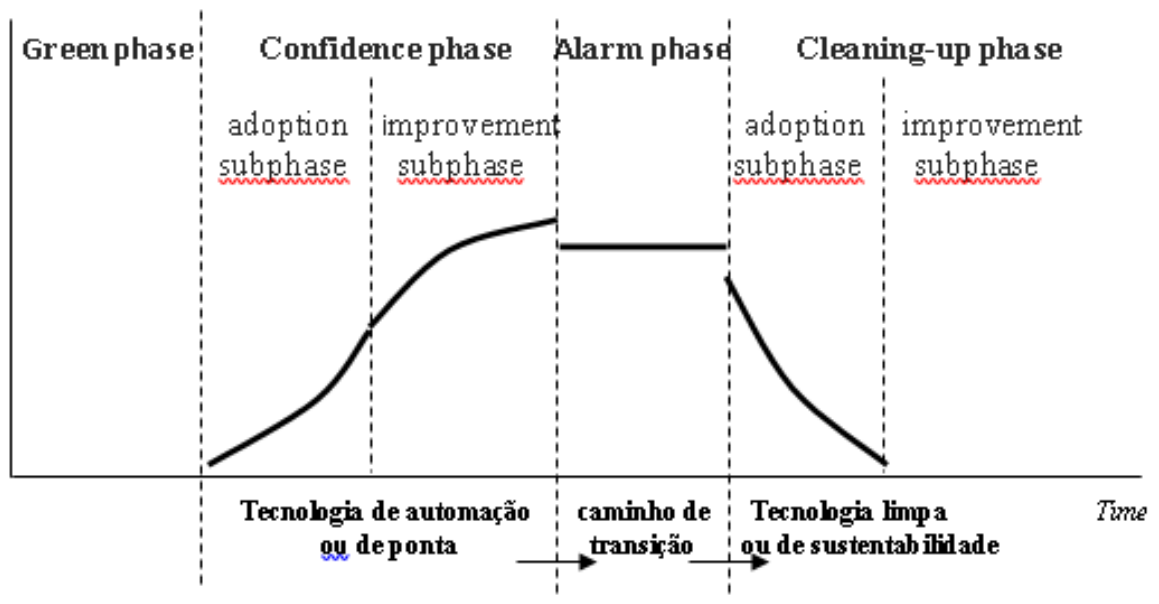

(Fonte: Adaptada de Egli, 2005)

A dinâmica do modelo pode ser explicada, genericamente, segundo o seu autor ${ }^{13}$ :

"In the first phase, the so-called "green phase", only one General Purpose Technology/GPT is available, which causes no pollution. In the second phase, a new GPT becomes available and is gradually adopted; this defines the "adoption subphase". Firms invest in the adoption of the new GPT since it saves on their labour costs. Once all sectors in the economy have adopted the new GPT, firms again invest in product quality improvements; this defines the "improvement subphase". Yet, to operate the new GPT, pollution cannot be avoided. As a result, pollution rises, first, with the adoption and, subsequently, with rising output. ... However, pollution is not yet recognized

13 Para uma completa explicação deste modelo ver Egli (2005). 
as a problem. ... The third phase starts once it becomes widespread. Correspondingly, the third phase is labeled "alarm phase". The government responds to the public's concern by taxing emissions. As a result, firms cut back production and pollution decreases. As soon as a new, clean GPT becomes available, a new phase of adoption starts. ... With its invention, the "cleaning-up phase" starts. The clean GPT is gradually introduced in the different sectors of the economy and pollution decreases in the course of time (during the adoption subphase). Ultimately, all firms have adopted the new, clean GPT and, therefore, pollution is absent and firms again invest to improve their product quality (improvement subphase). (EGLI, 2005:60)

O modelo desenvolvido por Egli apresenta o conceito da General Porpouse Technology-GPT (BRESNAHAN e TRAJEJTENBERT apud EGLI, 2005) que determina se a mudança tecnológica seria "pollution-saving" ou "pollution-using". E para este estudo, se a tecnologia está relacionada com a fase da tecnologia de automação ou de ponta ou com a fase da tecnologia limpa ou de sustentabilidade e como houve a transição de uma fase para outra.

O modelo de Egli adequou-se à afirmação de que a partir da percepção dos efeitos negativos gerados pelo progresso econômico, o qual é sustentado pelo progresso tecnológico, a mudança tecnológica passa a ser orientada para o uso sustentável dos recursos naturais e para a minimização das consequências do processo produtivo no meio ambiente.

A transição de uma fase para outra está, conforme se observa, na fase alarmante (alarm phase) onde o meio produtivo e o mercado iniciam um processo de ajustamento para o novo modelo de desenvolvimento, marcado por uma nova geração de tecnologias compromissadas com esse novo padrão de desenvolvimento.

O caráter teórico aqui apresentado encontra na literatura sinais empíricos ${ }^{14}$ de que já estamos vivenciando essa nova fase evolucionária da tecnologia.

Essa fase da evolução da tecnologia aparece como uma alternativa que deverá guiar, a nosso ver, os caminhos que a humanidade seguirá em sua odisséia através dos tempos e assim, possibilitar a sustentabilidade eterna para a vida no planeta.

A crença nesta afirmação não tem um apelo visionário, mas se baseia em uma realidade empírica. A escolha errada do rumo tomado pela humanidade demanda alternativas que possam levá-la ao caminho que conduzirá aos verdadeiros ideais iluministas da liberdade, igualdade e fraternidade também para as futuras gerações.

Mais uma vez o conhecimento disponível e transformado em novas tecnologias é o responsável pela abertura de uma nova estrada que nos conduz, através dos tempos, aos caminhos que a humanidade ainda deverá percorrer.

\section{CONCLUSÃO}

O estudo do fenômeno da tecnologia concluiu que ela teve um comportamento evolucionário durante o seu percurso na história da humanidade.

\footnotetext{
${ }^{14}$ Estudos realizados pela Environmetal Protection Agency-EPA (2002 e 2005) dos EUA e o Department for Environmet, Food and Rural Affairs-DEFRA (2005) do UK mostraram, para a nitrogen oxide emissions, $\left(\mathrm{NO}_{\mathrm{x}}\right)$ um comportamento típico apresentado pelo modelo para alguns paises selecionados.
} 
Partindo de uma função primitiva de subsistência na pré-história, a tecnologia alcançou uma relevância social e econômica na fase artesanal, atingindo uma importância econômica fundamental na fase mecanizada, até o ponto em que se tornou a razão de existência e de sustentação do padrão de desenvolvimento vigente na fase da automação.

Observou-se que durante os séculos a tecnologia vem aumentando sua participação como fator de progresso social e, em períodos mais recentes, econômico, o que levou a uma distorção do seu papel quando avaliamos os impactos do modelo de produção capitalista sobre o meio ambiente e social que foram observados no último quartel do século passado.

Neste ponto houve a necessidade de revisão do seu papel partindo-se do pressuposto de que ela está na base de um modelo condenado por suas conseqüências desastrosas.

Portanto, na fase da tecnologia de sustentabilidade, aparece uma nova relação entre o progresso tecnológico e o econômico e destes com o meio ambiente e o social, onde a geração de novas tecnologias deve considerar em seu processo o desenvolvimento sustentável.

Conclui-se ainda que há uma relação direta entre os progressos social, econômico, cultural e tecnológico e uma relação inversa entre o dinamismo tecnológico e o tempo de duração de cada fase identificada no período histórico.

Verificou-se, a partir das características das cinco fases apresentadas, que a evolução histórica mostrou como o progresso tecnológico de cada etapa se deu a partir das demandas que foram formuladas conforme cada contexto político, social, econômico e cultural de cada fase identificada.

Assim, as fases evolucionárias da tecnologia têm íntima relação com as fases da história humana - a Pré-História, a Antiguidade, a Idade Média, a Idade Moderna e a Idade Contemporânea - que possibilitaram as condições particulares para o progresso tecnológico em cada fase. Segundo Garcia et al. (2000) apud Verazto et al. (2008:71) "não há como negar que a tecnologia condiciona o tipo de sociedade que vivemos."

Com essa afirmação entende-se que as fases da tecnologia determinaram o contexto próprio e suficiente para a realização do progresso tecnológico em todas as fases da história humana.

O progresso tecnológico de uma fase, quando comparado ao período imediatamente anterior, se mostrou relativamente superior, fazendo com que o tempo de permanência da fase fosse cada vez menor à medida que o tempo passava. O dinamismo tecnológico e a sofisticação crescente encontrados nas novas tecnologias à medida que a humanidade evoluía, vêm alterando com maior rapidez o contexto particular que possibilitou o alcance do progresso tecnológico daquele momento.

Com isso, pode-se observar que a partir da terceira fase da evolução da tecnologia, a lógica imposta pelo Capitalismo e sua crescente necessidade de crescimento econômico, levou a uma rápida obsolescência ou sub-utilização das novas tecnológicas pois, em pouco tempo, inovações precisariam ser geradas para um novo ciclo de progresso econômico para garantir a sustentação do modelo capitalista de produção. 
Por fim esperamos que as conclusões aqui apresentadas contribuam para um melhor entendimento do papel da tecnologia e que esse trabalho se converta em uma contribuição perante a complexidade da evolução humana em sua saga de continuar avançando através dos tempos. 


\title{
Analysis of the evolution of technology: a contribution to the teaching of science and technology
}

\begin{abstract}
Although technology is an important tool for human interests, it is missing a full understanding of its evolution over time. The literature analyzes technological progress in a pre-established and punctual context, consequence of the cultural, economic, political and social aspects that influences the human effort in the generation of new technologies. The understanding of this evolution would allow us to understand its relation with the human development by the identification of its main phases from remote times to present day. It was not intended to make a study of technological progress, which is conditioned to particular contexts in a given time, but an analysis that considered a single process, the human history. It was identified five phases of changes in the evolution of technology. It was concluded that the technological dynamism, as a result of the evolution of technology, reduced the time of the first four phases in the historical process and that the last one is considered an ideal alternative that will lead the destinies of Humanity.
\end{abstract}

KEYWORDS: Technology. Technology evolution. Technology progress. 


\section{REFERÊNCIAS}

ANGOTTI, J. A. P.; AUTH, M. A. Ciência e tecnologia: implicações sociais e o papel da educação. Ciência \& Educação, v.7, n.1, 2001. p.15-27.

BARRA, D. C. C.; NASCIMENTO, E. R. P.; MARTINS, J. J.; ALBUQUERQUE, G. L.; ERDMANN, A. L. Evolução histórica e impacto da tecnologia na área da saúde e da enfermagem. Revista Eletrônica de Enfermagem, v. 08, n. 03, p. 422 - 430, 2006.

BASALLA, George. The evolution of technology. Cambridge History of Science Series. Cambrigde University Press. 1993.

BRASIL. Ministério do Meio Ambiente. Agenda 21 - C\&T para o desenvolvimento sustentável. Programa das Nações Unidas para o desenvolvimento sustentável. Projeto PNUD BRA/94/016. Brasília, junho de 1999.

CARMINHA, O. C.; ANDION, C. Sociologia da ciência: trajetória e atualidade de uma disciplina em renovação. VI Colóquio Internacional de Epistemologia e Sociologia da Ciência da Administração. Florianópolis/SC 26 a 28 de abril de 2017.

CASTELFRANCHI, Y.; FERNANDES, V. Teoria crítica da tecnologia e cidadania tecnocientífica: resistência, "insistência" e hacking. Rev. Filos., Aurora, Curitiba, v. 27, n. 40, p. 167-196, jan./abr. 2015.

CORIAT, B. Ciência Técnica e Capital. H. Blume Edições, Madrid, 1976, p.51-52.

COSTA, G. Ciência, tecnologia e sustentabilidade socioambiental. Revista Científica Hermes. vol. 1, julio-diciembre. 2009 (1).

DAGNINO, R. Enfoques sobre a relação ciência, tecnologia e sociedade. Revista de Ciência da Informação. V.3, n.6, dezembro 2002.

DICKSON, D. Tecnología alternativa y políticas del cambio tecnológico. Blume Ediciones, 1980, p. 11-15.

$E G L I, H$. The environmental kuznetz curve: theory and evidence (doctoral thesis). Zurich University, Zurich. 2005.

GAGNE, R. M. Instructional Technology: Foundations. Routledge, NY, 16 de dez de 2013. 
HOLLOWAY, J.; PELÁEZ, E. Aprendendo a curvar-se: pósfordismo e determinismo tecnológico. Revista Outburo, n. 2. São Paulo: Instituto de Estudos Socialistas, 1998. p.21-29.

LASTRES, H. M. M.; CASSIOLATO, J. E.; LEMOS, C.; MALDONADO, J.; VARGAS, M. A. Globalização e inovação localizada. In CASSIOLATO, J. E. e LASTRES, H. M. M. (eds.) Globalização e Inovação Localizada - Experiências de Sistemas Locais no Mercosul. Brasília: IEL/IBICT, 1999.

LIMA, K. M. Determinismo tecnológico. Revista Espiral Cibéria. Revista Eletrônica do Núcleo José Reis de Divulgação Científica - PTDC/CNPq. Ano 7, no.28/Jul- AgoSet de 2006.

LINSINGER, I. V.; SUZANI, C. Educação em cts em perspectiva discursiva: contribuições dos estudos sociais da ciência e tecnologia. Redes, vol. 16, n. 31 , Buenos Aires, Dez/2012, p. 163-182.

MARQUETTI, A. A. Progresso técnico, distribuição e crescimento na economia brasileira: 1955-1998. Est. Econ., São Paulo, 32(1):103-124, jan-mar 2002.

MARX, K. O capital: crítica de economia política. Coleção os Economistas. Ed. Nova Cultural, São Paulo. 1988.

QUELUZ, G. L.; QUELUZ, M. P. Memória, modernidade e tecnologia. Revista Educação \& Tecnologia. ISSN eletrônico 2179-6122, v. 2, n. 2, 2000.

REZENDE, C. História econômica geral. Editora Contexto. $4^{a}$ edição. São Paulo. 1999.

RODRIGUES, P. dos Santos, et al (orgs.). A universidade e a pesquisa: o público e o privado. UFRJ/ICB. Sonda; IURME/CASPAM. Rio de Janeiro. 1997.

SANDLER, R. L. (Editor). Ethics and emerging technologies. ISBN: 978-0-23036703-6 (Print) 978-1-137-34908-8 (online). Book. Palgrave Macmillan UK. 2014. 
SCHUMPETER, J. Alois. História da análise econômica. Ed. Fundo de Cultura S. A., Rio de Janeiro,.1964.

A teoria do desenvolvimento econômico: uma investigação sobre os lucros, capital, crédito, juro e o ciclo econômico. Coleção os Economistas. Ed. Nova Cultural, São Paulo. 1988.

VALLEJO, L. R. Ecodesenvolvimento e o mito do progresso. Terra Livre 4. 2015.

VERASZTO, E. V. Projeto Teckids: educação tecnológica no ensino fundamental. Dissertação de Mestrado. Campinas. Faculdade de Educação. UNICAMP. 2004.

VERASZTO, E. V; SILVA, D. da; MIRANDA, N. A.; SIMON, F. O. Tecnologia: buscando uma definição do conceito. Prisma.com ISSN: 1646-3153, nr. 7, 2008.

\section{Recebido: 2017-05-30}

Aprovado: 2018-08-28

DOI: $10.3895 /$ rbect.v11n3.5947

Como citar: HAYNE, L. A.; WYSE, A. T. Análise da evolução da tecnologia: uma contribuição para o ensino da ciência e tecnologia. Revista Brasileira de Ensino de Ciência e Tecnologia, v. 11, n. 3, 2018. Disponível em: <https://periodicos.utfpr.edu.br/rbect/article/view/5947>. Acesso em: xxx. Correspondência: Luiz Augusto Hayne - luizhayne2012@gmail.com Direito autoral: Este artigo está licenciado sob os termos da Licença Creative Commons-Atribuição 4.0 Internacional.

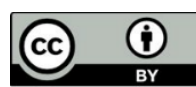

